\title{
Call for paper for sustainability science and implementing the sustainable development goals
}

\author{
Kazuhiko Takeuchi ${ }^{1} \cdot$ Braden Allenby $^{2} \cdot$ Thomas Elmqvist $^{3} \cdot$ \\ Anantha Kumar Duraiappah ${ }^{4} \cdot$ Joanne Kaufman $^{5}$. Norichika Kanie ${ }^{6}$. \\ Shunsuke Managi ${ }^{7} \cdot$ Osamu Saito $^{8}$
}

Published online: 2 February 2016

(C) Springer Japan 2016

\section{Introduction}

Sustainability science probes interactions between global, social, and human systems, the complex mechanisms that lead to degradation of these systems, and concomitant risks to human well-being. As a transdisciplinary academic discipline, it can point the way to a sustainable global society by identifying and addressing complex challenges that traditional academic disciplines have not addressed.

As it can no longer be considered a new field, it is the right time to take stock of what we have learned in recent sustainability science research, and how to apply this to the sustainability challenge of our time, which is the success of the Sustainable Development Goals (SDGs).

The SDGs combine efforts to eradicate poverty and increase the development of poor countries with decreasing

Osamu Saito

saito@unu.edu

1 United Nations University and Integrated Research System for Sustainability Science (IR3S), The University of Tokyo, Tokyo, Japan

2 Arizona State University, Tempe, AZ, USA

3 Stockholm Resilience Centre, Stockholm University, Stockholm, Sweden

4 UNESCO Mahatma Gandhi Institute of Education for Peace and Sustainable Development (MGIEPI), New-Delhi, India

5 Massachusetts Institute of Technology (MIT), Fox Amphoux, France

6 Keio University, Tokyo, Japan

7 Kyushu University, Fukuoka, Japan

8 United Nations University Institute for the Advanced Study of Sustainability (UNU-IAS), Tokyo, Japan the human footprint on the environment. They will take a more inclusive and diverse approach by mobilizing actors in both developed and developing countries. Now serious sustainable development problems dominate policy discussion in many countries, but with little actual results in terms of complex global environmental problems like climate change. Where progress in social indicators is made, it often comes at an environmental cost. Inter-linkages across different goals will be a challenging area of research, and the inherent trade-offs and complexity of such an effort require that related policies be informed by a science of sustainability. New accounting measures will be required to monitor implementation of SDGs, such as with an inclusive index of well-being ${ }^{1}$ by including natural and human capital as well as manufactured capital into national accounts. The SDGs and progressively more inclusive accounting methods are a response to the rather narrow focus on economic growth that creates inequality and undermines sustainability, and there is a need for research into how measuring wealth inclusively can support SDG implementation.

This special issue presents a critical analysis of the SDGs from the perspective of how the science community can best contribute to their implementation through scenario analysis, stakeholder partnerships, regional analyses, and ultimately policy impact.

\footnotetext{
${ }^{1}$ The Inclusive Wealth Index (IWI) looks at the productive base of economies based on capital assets-produced or manufactured capital, human capital, and natural capital. IWI compares the broader value of capital in societies. UNEP and UNU-IHDP have jointly published Inclusive Wealth Report (IWR) in 2012 and 2014, the latest covering 140 countries (UNU-IHDP and UNEP, 2012, 2014).
} 


\section{Aims and scope}

The aim of this special feature is to present a scientific analysis of the SDGs with one focus being the contribution of sustainability science analysis, and the other the social science dimension of SDGs and inclusive wealth, in an attempt to understand how major targets can be achieved.

The special feature will start with a group of papers from the Sustainability Science Symposium in Tokyo, Japan in 2016, and welcomes additional contributions on the following themes:

- Science-based assessments of the SDGs with policyrelevant guidance on implementation.

- Inclusive growth, inclusive wealth, and sustainable development index.

- The sustainability of population growth.

- Global and country analysis on implementing SDGs.

This special feature is not limited to global analysis, and open submissions on country or regional analysis related to SDGs or inclusive wealth are encouraged. Reflections on Millennium Development Goals related to SDGs can be also accepted. Sustainability Science accepts various forms of contributions, from original research articles, to case studies, methodological advancements, as well as timely assessments of the state of knowledge and commentaries. See paper categories here: http://www.springer.com/11625.

\section{Deadlines, submission, and review process}

Authors are encouraged to submit extended abstracts to the special feature editors. Upon acceptance authors will be invited to submit full manuscripts through the journal's electronic editorial management system, keeping in mind publisher formatting guidelines and length requirements. At this point, authors should state they are submitting their work to be considered for the "Sustainable Development Goals and Inclusive Wealth of Nations" special feature. Papers will go through a blind review.

Submit abstracts to: SSSFISDG@gmail.com Important Dates

June 30, 2016-Submission of extended abstracts.

September 30, 2016-Submission of full papers.

Spring 2017-Expected publication of special feature.

\section{References}

Inclusive Wealth Index. https://iwr.squarespace.com/introduction2012

UNU-IHDP and UNEP (2012) Inclusive Wealth Report 2012. Measuring progress toward sustainability. Cambridge University Press, Cambridge. http://www.unep.org/pdf/IWR_2012.pdf

UNU-IHDP and UNEP (2014) Inclusive Wealth Report 2014. Measuring progress toward sustainability. Cambridge University Press. Cambridge. http://mgiep.unesco.org/wp-content/uploads/ 2014/12/IWR2014-WEB.pdf 